\title{
The relationship between mobile learning and self-regulated learning: A systematic review
}

\author{
Agnieszka Palalas, Norine Wark \\ Athabasca University, Canada
}

A systematic review of 38 primary research peer-reviewed articles, drawn from six databases and spanning from January 2007 to January 2019, was conducted to determine the principle information that they collectively offered on the relationship between mobile learning (mlearning) and self-regulated learning (SRL). In answering the research questions posed, a synthesis of the following 12 key elements was undertaken: (1) research aims, (2) research methodologies, (3) outcomes, (4) education discipline areas, (5) educational levels, (6) educational contexts, (7) geographic location, (8) time frame, (9) type of device, (10) m-learning and SRL definitions, (11) theoretical models, and (12) m-learning, self-regulation (SR), and SRL variable measurement instruments. The frequency of studies on the relationship between $\mathrm{m}-$ learning and SRL increased in more recent years, as did the types of devices used in these studies. More than three quarters of the studies concluded that m-learning enhanced SRL, SRL enhanced m-learning, or m-learning and SRL enhanced other learning factors (e.g., health, curriculum development). Moreover, the relationship between m-learning and SRL was dynamic and complex. A primary recommendation was to intentionally integrate m-learning and SRL into formal curricula guided by informed, technologically adept educators who provided appropriate, ever-decreasing support and scaffolding as learners became more self-determined.

Implications for practice or policy:

- M-learning research and practice should be founded upon relevant theory and validated definitions of m-learning that consider ever-advancing technologies and related pedagogies that include participatory activities.

- M-learning designers should ensure that mobile technologies are used intentionally and selectively, guided by clearly defined learning objectives, and integrated into the curriculum by technologically adept educators who provide appropriate, ever-decreasing support and scaffolding as learners become more self-determined.

- When designing m-learning, educators should consider digital safety and privacy issues.

Keywords: formal education, m-learning, mobile learning, self-regulation, self-regulated learning, thematic synthesis, systematic review

\section{Introduction}

Self-regulated learning (SRL) has been explored extensively in various educational settings since the 1980s, and also in relation to mobile learning (m-learning) in more recent years. While SRL skills have been found to be a significant predictor of academic achievement, research continues to explore new dimensions of "how students become masters of their own learning processes" (Zimmerman, 2008, p. 166). This systematic review offers a current summary of what primary research studies from peer-reviewed journal articles have found on the relationship between m-learning and self-regulated learning. There are numerous systematic reviews exploring the use of m-learning in specific fields, for instance in higher education (e.g., Crompton \& Burke, 2018; Krull \& Duart, 2017; Pimmer, Mateescu, \& Grohbiel, 2016) or in health education (e.g., DiFilippo, Huang, Andrade, \& Chapman-Novajofski, 2015; Dunleavy et al., 2019) as well as those publications reviewing diverse m-learning applications (e.g., Kumar \& Mohite, 2018; Mosa, Yoo, \& Sheets, 2012), or exploring mlearning through a variety of other lenses. At the same time, numerous systematic reviews have addressed the concept of SRL in different digital learning contexts (e.g., Alonso-Mencía et al., 2019; Broadbent \& Poon, 2015; Wong et al., 2019); however, none of the reviews examined how self-regulated learning and m-learning may impact each other. The purpose of this review is to address the gap in the literature that the authors 
identified when exploring the said relationship. This succinct summary of research on the topic may inform and direct m-learning initiatives that enhance, rather than impede the relationship between m-learning and SRL.

\section{Theoretical constructs and definitions}

\section{Self-regulated learning}

According to Zimmerman (2008), a key theoretician of SRL, self-regulated learning refers to "the self-directive processes and self-beliefs that enable learners to transform their mental abilities, such as verbal aptitude, into an academic performance skill, such as writing" (p. 166). SRL is comprised of proactive processes that are needed to acquire academic skills derived from the learner's "advantageous motivational feelings and beliefs as well as metacognitive strategies" (p. 167). These proactive processes include goal setting, strategy selection and use, as well as self-monitoring (Zimmerman \& Schunk, 2001).

Panadero (2017) highlights the various dimensions of SRL, including its cognitive, metacognitive, behavioural, motivational, and emotional aspects, and how they interconnect to influence learning. When examining SRL, Panadero recommends consideration of interrelated variables (e.g., self-efficacy, volition, cognitive strategies) using "a comprehensive and holistic approach" (p. 422). Discussion of SRL definitions and other information shared by the reviewed articles offers a more comprehensive explanation of the many aspects of SRL and their relationship to m-learning.

\section{Mobile learning}

M-learning is widely understood as learning across locations and contexts using personal devices (Crompton, 2014; Pegrum, 2014; Sharples et al., 2007). Using this perspective as a starting point, this study focused on the mobility of the learner (Palalas \& Wark, 2017; O’Malley et al., 2003; Sharples, 2000; Sharples, Taylor, \& Vavoula, 2007; Traxler, 2007) and his/her digital technology-enabled learning experiences, not restricted to any particular type of technology (e.g., mobile phones, wearables, augmented reality, virtual reality). Over time, the mobile technologies that gave birth to the concept of m-learning have impacted the characteristics and possibilities of m-learning research and practices, resulting in a progression from content-oriented to increasingly interaction-oriented learning, guided by more active pedagogies (Rodger \& Glover, 2018). Advancements in digital technologies have enhanced the scope of m-learning and its accessibility. At the same time, mobile technologies can be very intrusive. By shaping when and where people communicate, compute, capture, and create educational content (Quinn, 2012), and how people learn, these technologies may shape the experience of learning. How people use technologies (and are often expected to use them) may increase efficiency and effectiveness of accessing and interacting with information, but may also affect the autonomy of the learners, motivating or demotivating them, and thus impact their learning process and outcomes.

\section{Research design}

A systematic review (Hemingway \& Brereton, 2009), involving the selection, identification, and synthesis of primary research studies, was conducted to answer the research questions guiding this study. This study used a systematic, explicit, replicable methodology employing a series of protocols known as the "Preferred Reporting Items for Systematic reviews and Meta-Analyses for Protocols 2015 (PRISMA-P 2015) (Moher et al., 2015) to: (1) identify and select relevant research, and (2) analyse and synthesise the data from the pertinent studies. The goal was to provide an exhaustive review and impartial synthesis of the literature (Gough, Oliver, \& Thomas, 2012; Oakley, 2012) to present a reliable depiction of the reviewed studies.

\section{Research questions}

This study sought to answer the following questions:

1. What are the major research aims, methods, and outcomes in studies on the interrelationship between m-learning and SRL? 
2. What are the educational discipline areas, levels, and contexts in studies on the interrelationship between m-learning and SRL?

3. What were the geographic locations, time frames, and types of mobile devices used in studies on the interrelationship between m-learning and SRL?

4. What are the most prevalent definitions used for the terms, mobile learning, and self-regulated learning in studies on the interrelationship between m-learning and SRL?

5. What models and variable measurement instruments for $\mathrm{m}$ - learning and self-regulated learning are most commonly found in studies on the interrelationship between m-learning and SRL?

\section{Search parameters}

Search parameters were defined by four subtopic areas: search strategy, study selection, inclusion and exclusion criteria, and analysis framework.

\section{Search strategy}

The following electronic databases/search engines were used to generate peer-reviewed journal articles on primary empirical research for this review because they are large, well-known databases in the field of education and educational technology: ACM, Google Scholar, ScienceDirect, Springer, Taylor \& Francis Online, and Web of Science Core Collection. Reference sections from the studies collected in this initial search were then examined for other potentially eligible studies. Reference sections in new studies discovered during this stage were also reviewed for further candidates. Email alerts were set up for each database that offered this service as well. A final Google Scholar search was done on January 31, 2019, (just before data analysis began) to capture any new articles that may have been published after the previous rounds of searching and to ensure saturation.

Search terms that included combinations of one m-learning and one SRL keyword (e.g., "mobil" AND "selfregulat*") were used to find relevant primary studies via the electronic databases. The capture of studies employing variations of keywords during searches was ensured by using prefix-based keyword searches. Mlearning key words included: mobil* (an asterisk indicates a prefix-based keyword), mobile, mlearn, and mlearn. Keywords for learner self-regulation included: self-regulat*, self-regulate, and self-regulation.

\section{Study selection and inclusion/exclusion criteria}

The search was limited to publications between 1 January 2007 and 31 January 2019. The year, 2007, was chosen as the starting point since this was when the first large-scale m-learning field study was conducted (Parsons, 2014). Each study had to meet all of the inclusion criteria and none of the exclusion criteria in Table 1 to be part of this systematic review.

Table 1

Inclusion/exclusion criteria

\begin{tabular}{ll}
\hline Inclusion criteria & Exclusion criteria \\
\hline Article was original research & Conference proceedings journal articles \\
Article came from peer-reviewed English language & Systematic review articles \\
journal & \\
$\begin{array}{l}\text { Article included in m-leaning and SRL } \\
\text { Research was conducted within formal education } \\
\text { settings }\end{array}$ & $\begin{array}{l}\text { Articles not related to learning } \\
\text { Articles that did not include mobile technologies }\end{array}$ \\
& $\begin{array}{l}\text { Articles on gaming devices that may not have been } \\
\text { mobile }\end{array}$ \\
\hline
\end{tabular}

The authors began by searching one database together to establish searching protocols, and inclusion/exclusion criteria (Figure 1). Titles resulting from the initial keyword search were sorted together and then a sample of abstracts was selected to also review together. Next, the authors independently sorted abstracts from remaining titles into three categories: (1) keep for full review, (2) reject, or (3) unsure. The authors reconvened to discuss 
sorting results and finalise decisions on which category each article belonged to, based upon abstract analyses. A second database was then searched, and $25 \%$ of the resulting titles were reviewed together. The remaining titles were split between the authors to review alone before reconvening to determine final results. The authors then divided the remaining databases to search alone. In total, keyword searches yielded 2015 unique titles, of which 263 appeared to be potentially relevant. Abstracts from the keep and unsure title categories were initially sorted alone. Results produced $90 \%$ inter-coder agreement between authors. Articles with abstracts in the unsure category were retained for full-text review. In total, 71 articles were kept for full-text review. The authors analysed a sample of these articles together, based on the systematic review research questions, inclusion/exclusion criteria, and methodological rigour (e.g., article cohesion between research questions, methods, instruments, and findings). The remaining articles were divided for independent analysis. The authors then reviewed each other's full-text findings. This yielded $97.8 \%$ intra-coder reliability. A total of 38 articles were kept for data analysis.

\section{Selection of Relevant Academic Peer-reviewed Journal Articles}

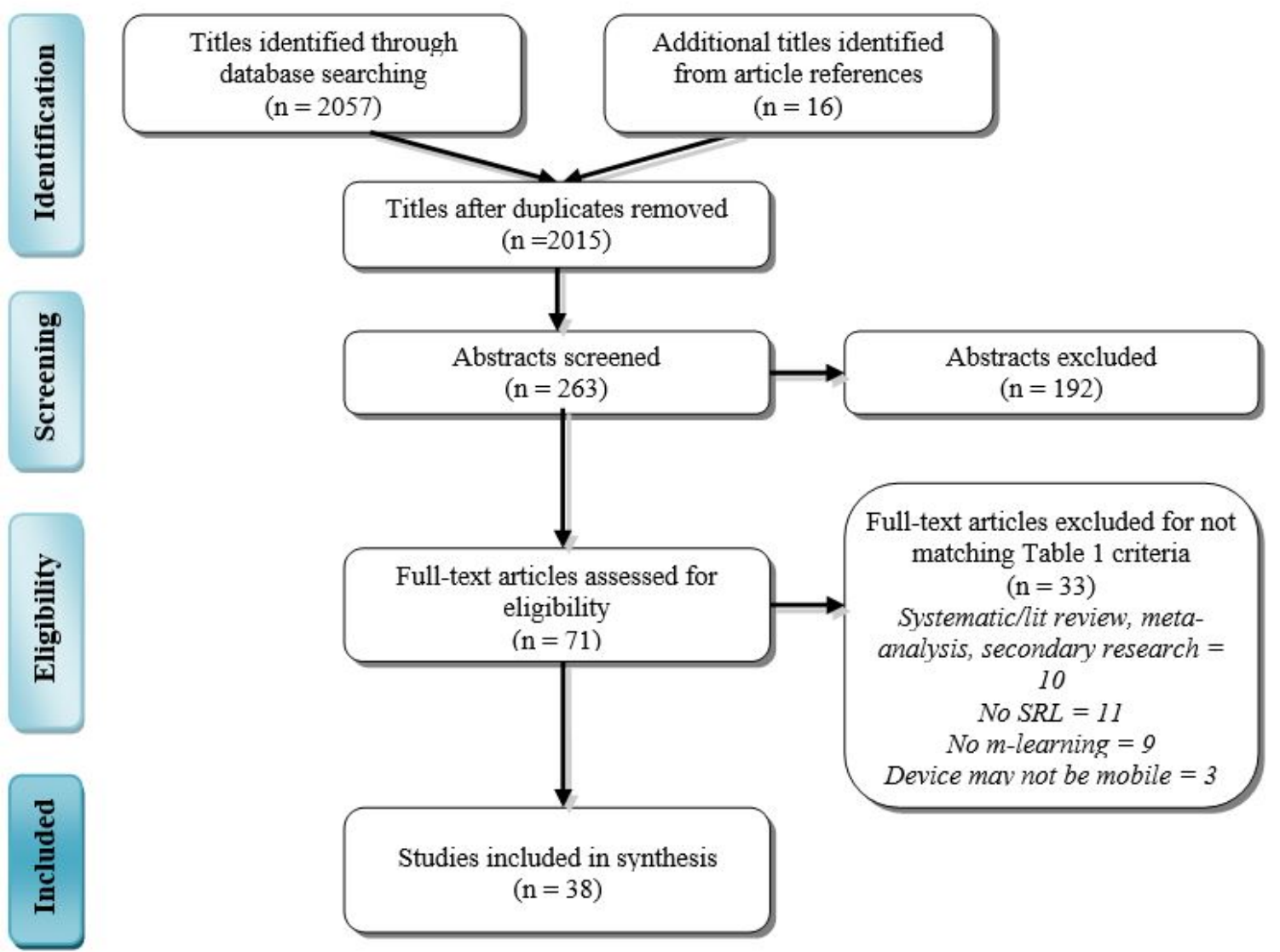

Figure 1: Selection of relevant academic peer-reviewed journal articles. Adapted from Preferred Reporting Items for Systematic Reviews and Meta-Analyses: The PRISMA Statement (Moher, Liberati, Tetzlaff, Altman, \& The PRISMA Group, 2009).

Analysis framework

The analytical framework included the 12 keys elements of: (1) research aims; (2) research methodologies; (3) research outcomes; (4) education discipline areas; (5) educational levels; (6) educational contexts (7) geographic location, (8) time frame, (9) type of device, (10) m-learning and SRL definitions, (11) theoretical models, and (12) m-learning, self-regulation (SR), and SRL variable measurement instruments. 


\section{Coding}

Coding in systematic reviews provides third-order constructs by interpreting and analysing data from the included studies (Britten et al., 2002). To ensure the integrity of study representation, the authors strove to preserve the original meaning and context of the raw data during secondary analysis (Sandelowksi, Voils, Leeman, \& Crandlee, 2011). NVivo Pro 11 v.23 and Excel 2010 software were used for coding purposes.

\section{Results and discussion}

Key findings from the synthesis of data analysis results and related discussion are organised by research question and related question elements.

\section{Question 1. Research aims, methods, and outcomes}

\section{Research aims}

Three broad research aim themes were identified. The most frequent theme focused on strategies $(n=16$ articles, or $42.1 \%$ of the studies). Eight of these explored how m-learning could enhance SRL, while five considered how m-learning and SRL could improve learning. The second most prevalent theme concerned impacts $(n=$ $12 ; 31.6 \%$ ). Five explored the impact of m-learning on SRL, while three examined the impact of SRL on mlearning. The final theme was on relationships $(n=10 ; 26.3 \%)$. Six studies were on the relationship between mobile device use, SRL, and other factors (e.g., mental health, learner modalities). The remaining four investigated the relationship between m-learning, SRL, and other factors (e.g., gender, learner dependence). While earlier strategy or relationship studies tended to focus upon how m-learning impacted SRL or vice versa, more recent studies considered the combined impact of m-learning and SRL on other learning factors (e.g., health, curriculum development), perhaps suggesting a growing awareness of the extent of interrelation between m-learning and SRL.

The authors anticipated that the aims of these studies would primarily be on how m-learning influenced SRL. While this may have been the case in approximately half of the studies, the remaining studies either explored how SRL influenced m-learning, or how both of these elements related to other learning factors. Perhaps most interesting was the discovery that more recent studies tended to consider the combined influence of m-learning and SRL on other learning factors. This suggested a significant shift in the understanding of the relationship between m-learning and SRL, and how this potentially complex interrelationship influenced other learning factors.

\section{Research methods}

Analysis of research paradigms and methodologies used in many studies would have required significant interpretation on behalf of the authors since these studies did not provide such details. Thus, to preserve the integrity of the raw data, only research methods were considered because they were overtly stated or easily interpreted. Twenty studies (52.6\%) (Figure 2) were quantitative in nature. Seventeen (44.8\%) were mixed methods. The remaining one $(2.6 \%)$ was a qualitative study. Twenty studies $(52.6 \%)$ were cross-sectional and longitudinal, $10(26.3 \%)$ were cross-sectional, and $8(21.1 \%)$ were longitudinal. Twelve studies $(31.6 \%)$ used mixed methods, incorporating cross-sectional and longitudinal data collection methods. Eight (21.1\%) quantitative studies employed either cross-sectional, or cross-sectional and longitudinal collection methods. The widespread use of mixed methods research in these studies, coupled with the extensive merger of quantitative or mixed methods research with cross-sectional and longitudinal methods, assists in providing an exploratory, confirmatory, triangulated, and therefore, comprehensive understanding of the relationship between m-learning and SRL (Cohen, Manion, \& Morrison, 2011; Onwuegbuzie \& Leech, 2005; Pimmer et al., 2016). 


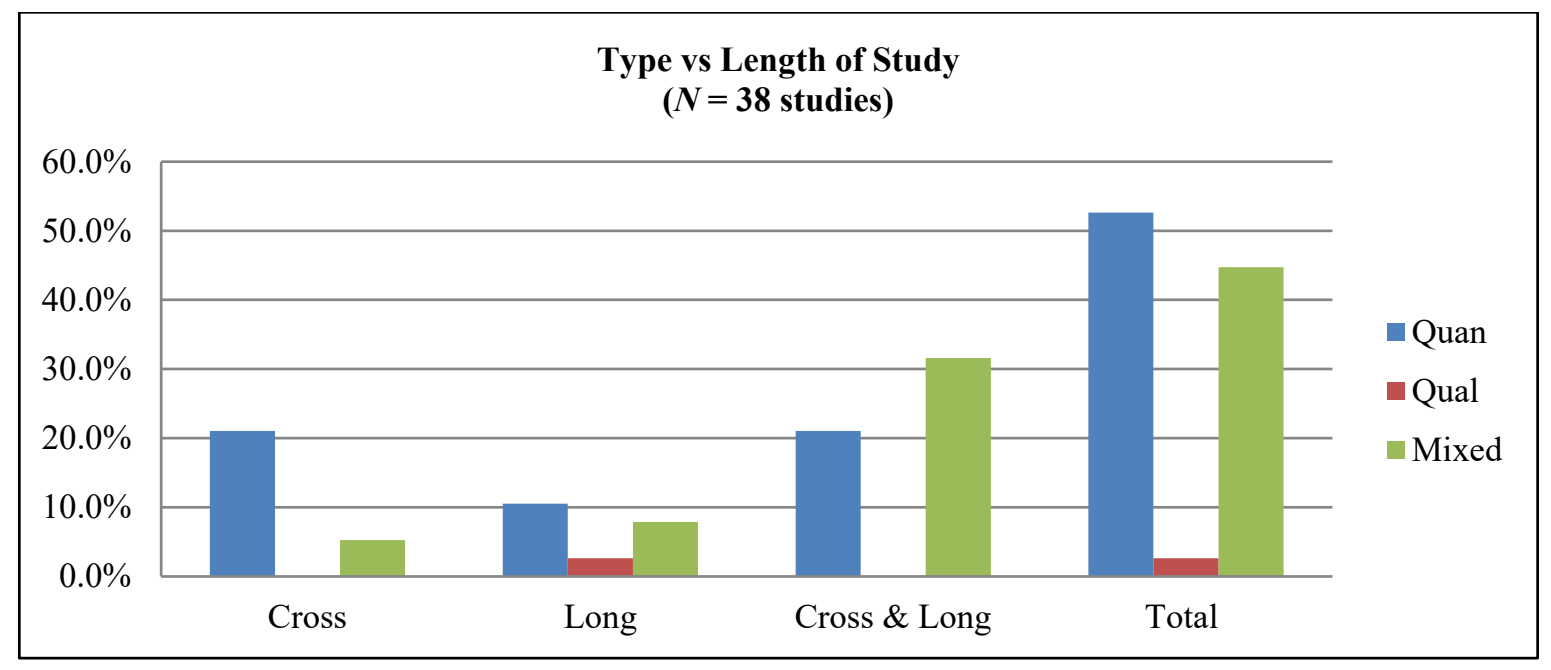

Figure 2. Type (quantitative, qualitative, or mixed) versus length (cross-sectional, longitudinal, or both) of study $(N=38)$

\section{Research outcomes}

Research outcomes were categorised by the most prevalent findings reported in the studies. Three categories were assigned: (1) enhanced learning, (2) neutral (inconclusive results), or (3) deterred (inhibited) learning. For instance, Chien's (2016) study concluded that m-learning enhanced learning by enabling learners to control learning processes, select pertinent resources and strategies, and become independent, self-motivated learners. However, learners felt that initial language instruction should be delivered in class without the use of mobile devices. Given that the most significant and greatest quantities of findings in this study were on how m-learning enhanced SRL, the outcome for this study was categorised as enhanced learning.

Twenty-nine studies (76.3\%) reported that m-learning and/or SRL enhanced learning outcomes (Figure 3). Fourteen $(36.8 \%)$ concluded that the relationship between m-learning and SRL enhanced other learning factors (e.g., health) or that the interrelationship between m-learning, SRL, and other learning factors (e.g., curriculum development) enhanced learning. Ten (26.3\%) concluded that m-learning enhanced SRL. Remaining studies in the enhancement category determined that SRL was enhanced by the use of mobile devices $(n=2 ; 5.3 \%)$, SRL improved m-learning $(n=2 ; 5.3 \%)$, or that SRL encouraged mobile device use $(n=2 ; 2.6 \%)$. A further $13.2 \%$ of all studies $(n=5)$ indicated neutral findings. Three of these studies $(7.9 \%)$ were inconclusive about the effect that mobile device use had on SRL; the other two $(2.6 \%$ each) reported neutral findings on the impact of $\mathrm{m}$ learning on SRL or vice versa. The final four (10.5\%) concluded that mobile device use deterred SRL. 


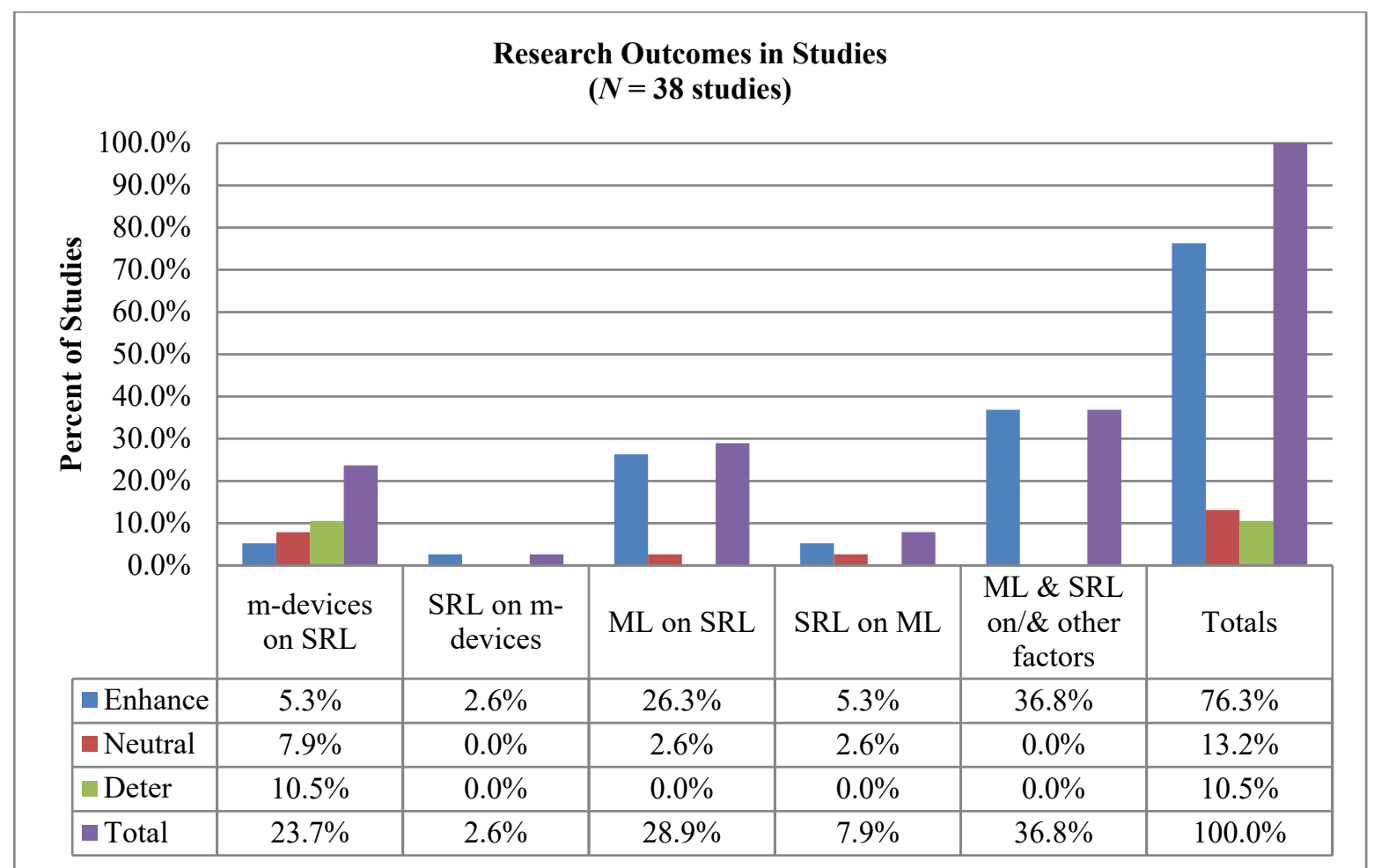

Figure 3. Prevalent research outcomes by percent $(N=38)$

\section{Question 2. Discipline areas, levels, and contexts}

\section{Discipline areas}

Eleven studies focused on foreign languages (e.g., English, Chinese; 28.9\%; Figure 4). Ten studies (26.3\%) involved multiple disciplines. Science was the third most dominant discipline area $(n=6 ; 15.8 \%)$.

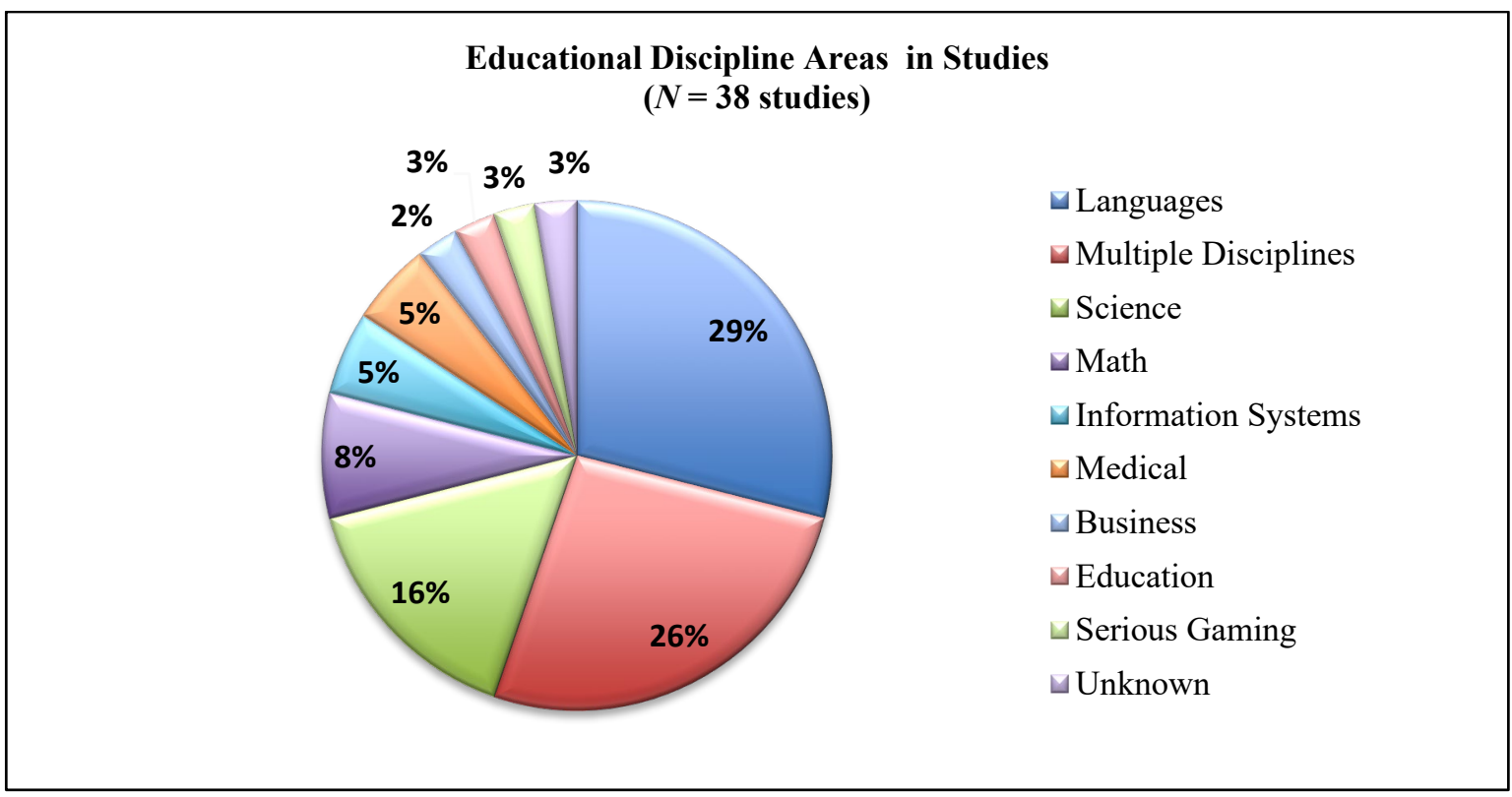

Figure 4. Educational discipline areas included in studies $(N=38)$ 
Education levels

Eighteen studies (47.4\%) involved undergraduate university students. Nine (23.7\%) focused upon elementary school children. Four $(10.5 \%$ each) had either high school or college level participants. Two included undergrad and graduate students $(5.3 \%)$, and one $(2.6 \%)$ included grad students only.

\section{Education contexts}

Educational contexts were separated into three categories: (1) formal, (2) informal, and (3) blended learning environments, as defined by Wark (2018). Formal learning included structured learning, typically delivered via a governing body-sanctified curriculum, often within institutionalised settings (e.g., public schools and universities). Informal learning encompassed incidental or casual learning; learning that occurred outside of formal learning contexts). Blended learning was viewed as the merger of distance (increasingly digital, online, and/or mobile) learning, and formal or informal face-to-face learning experiences.

Twenty-three studies $(60.5 \%)$ were conducted in blended learning contexts. Ten $(26.3 \%)$ were carried out in formal contexts. The final five (13.2\%) engaged informal learning contexts. The concentration of studies conducted in blended learning contexts may suggest a heightening recognition of the holistic nature of learning, supported by increasingly ubiquitous technologies that enhance m-learning opportunities (Berge \& Muilenburg, 2013).

\section{Question 3. Geographic location, time frames, and types of mobile devices}

\section{Geographic locations}

The studies were conducted in 24 countries (Figure 5). The country that the study authors came from was used when it was not overtly stated in what country a study was conducted. A question mark and purple colouring indicates study authors by country. Countries overtly identified were indicated in green. The highest number of studies occurred in Taiwan - seven studies (18.4\%) and in the USA - five (13.2\%). The absence of studies from Central and South America, Africa, Middle East, Asia Pacific, and Pacific Island areas is likely due to the selection of English-language articles for this review, which is an acknowledged limitation of this review. 


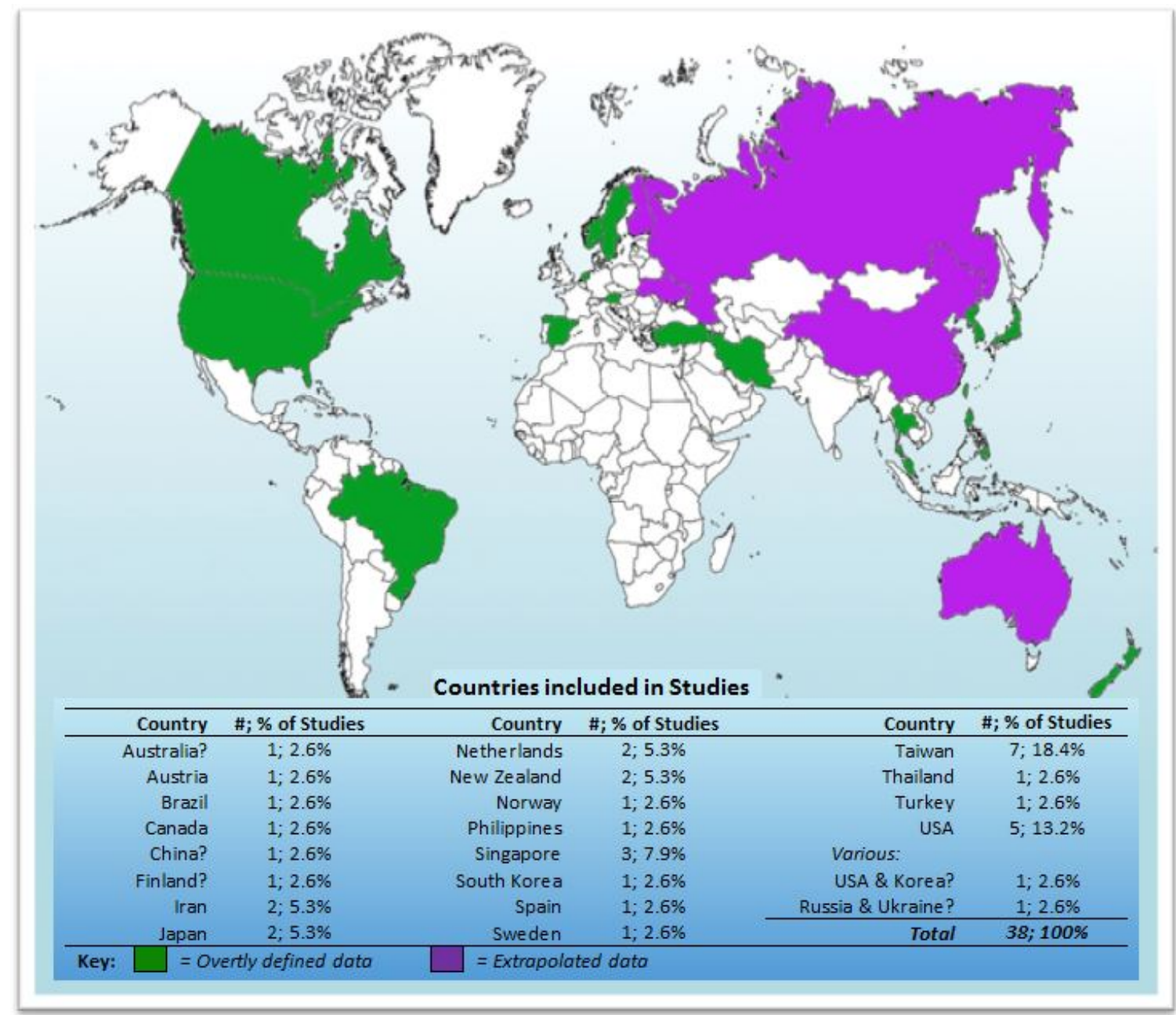

Figure 5. Countries included in studies $(N=38)$

\section{Time frames}

The year in which this research was undertaken was reported in half of the studies. In these studies, the time frame between the research year and publication year ranged between zero and 6 years, with four out of five publications occurring within 3 years of when the study was conducted. With this in mind, it was decided to use the publication year for reporting purposes. In general, the number of studies increased over the years (Figure 6). This may be partly due to the burgeoning ubiquity of mobile devices over the same period of time (International Telecommunications Union [ITU], 2018) which may, in turn, prompt growing interest in the relationship between m-learning and SRL.

The length of data collection periods during studies varied from less than 1 day to 3 years. The most common time period was one semester (approximately 13 weeks; $n=12 ; 31.6 \%$ ). Seven of the eight studies that were quantitative and cross-sectional in nature were completed in less than 1 day. Three studies (7.8\%) did not specify the length their data collection periods. 


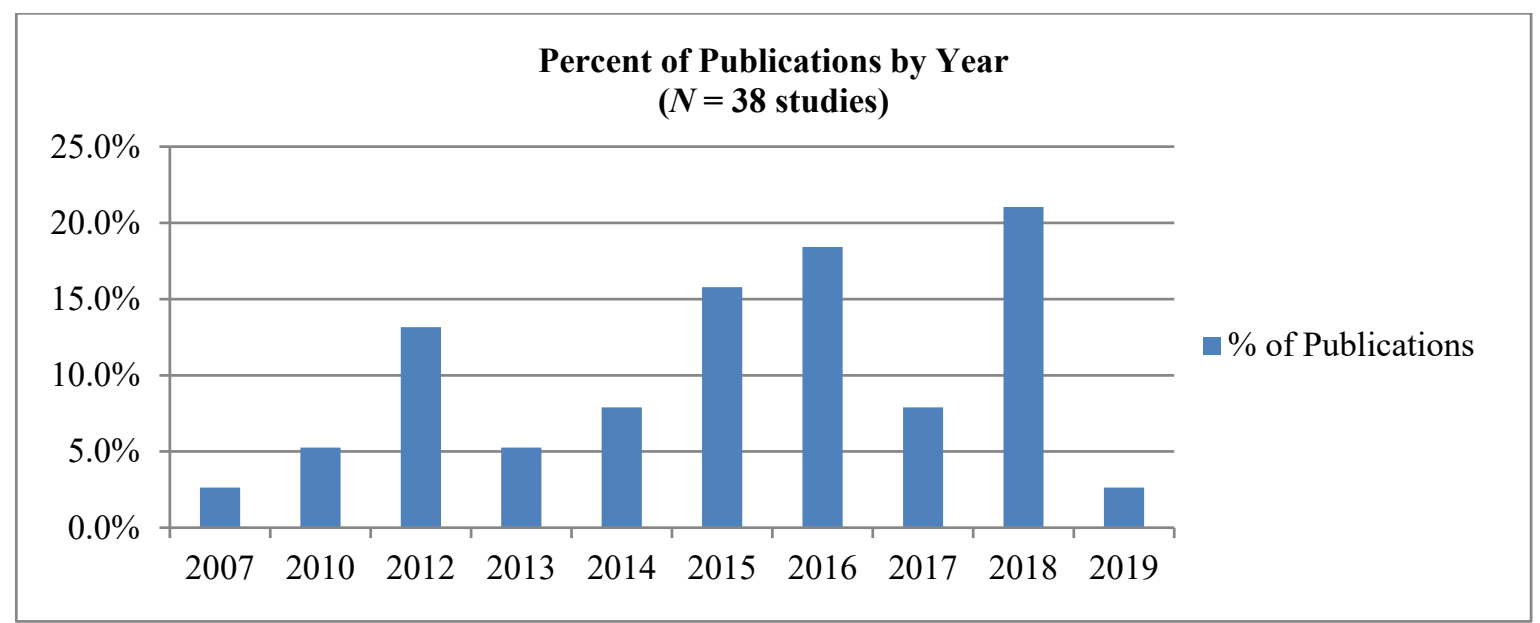

Figure 6. Percent of studies published by year (2019 includes only January; $N=38$ )

Types of mobile devices

Twenty-seven studies (71\%) reported using one or more mobile devices, $9(23.6 \%)$ used two, and $2(5.3 \%)$ used three. Twenty-seven studies used smartphones, 15 used tablets, and 7 used other devices, such as iPods and wearables. The devices used in $8(21 \%)$ studies were not specified.

When device type was compared to year of study, it was noted that half of the years included studies using two or more devices (Figure 7). Most of these studies occurred in more recent years, with the exception of 2015, which did not have studies that used more than one device. Moreover, the years 2014, 2016, 2018 , and 2019 included studies that examined smartphone, tablet, and other devices use. This trend may be explained by the exponential growth in the types of, and ubiquitous nature of emerging technologies across the globe (Brynjolfsson \& McAfee, 2014; ITU, 2018).

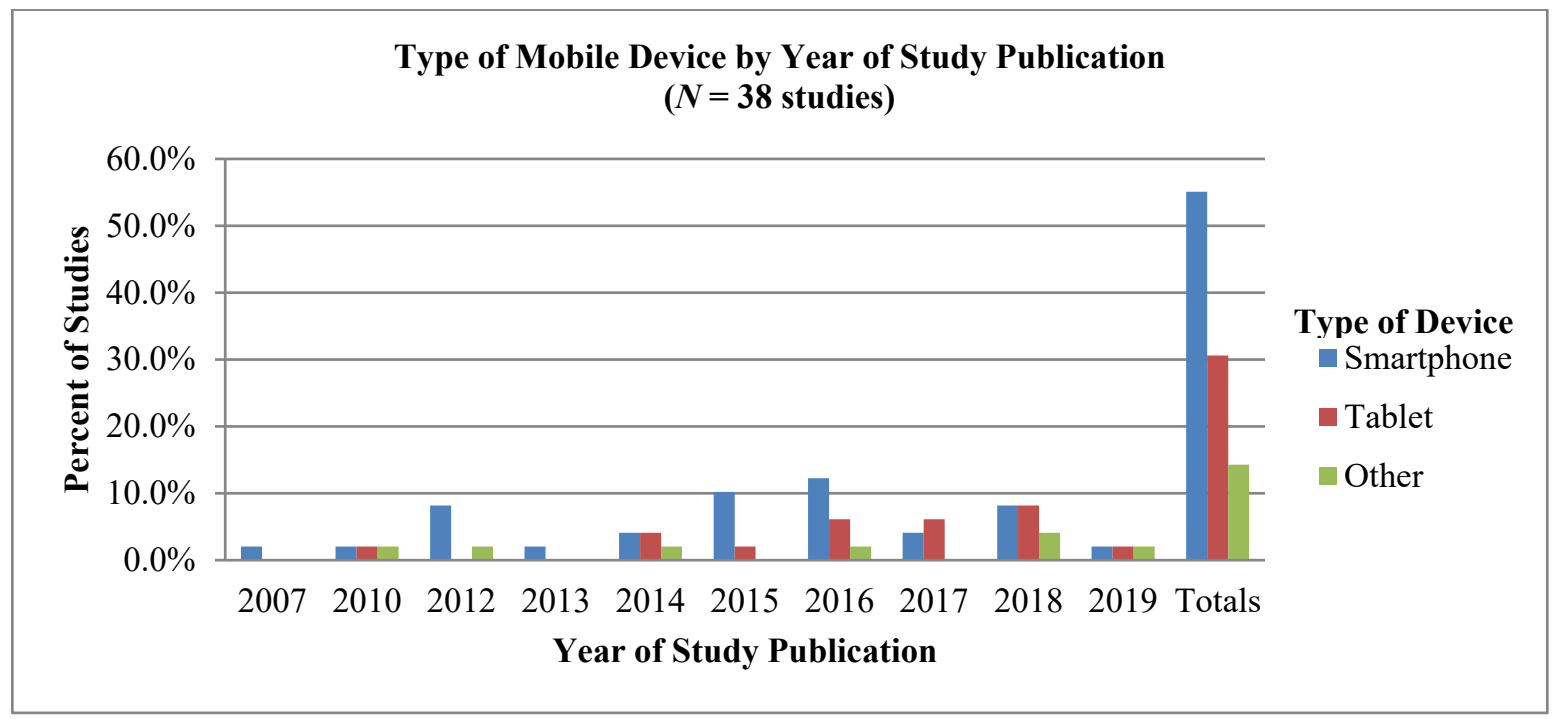

Figure 7. Type of mobile device used by year of publication for each study $(N=38)$

Note: This chart includes only the 49 mobile devices that were clearly identified by study authors. 


\section{Question 4. Definitions for mobile learning and self-regulated learning}

Nine (23.7\%; Figure 8) of the studies included definitions for SRL. Eight (21.1\%) included definitions for mlearning, or m-learning and SRL. Seven included definitions for self-regulation (SR; 18.4\%), and six (15.8\%) contained no definitions for any of these terms.

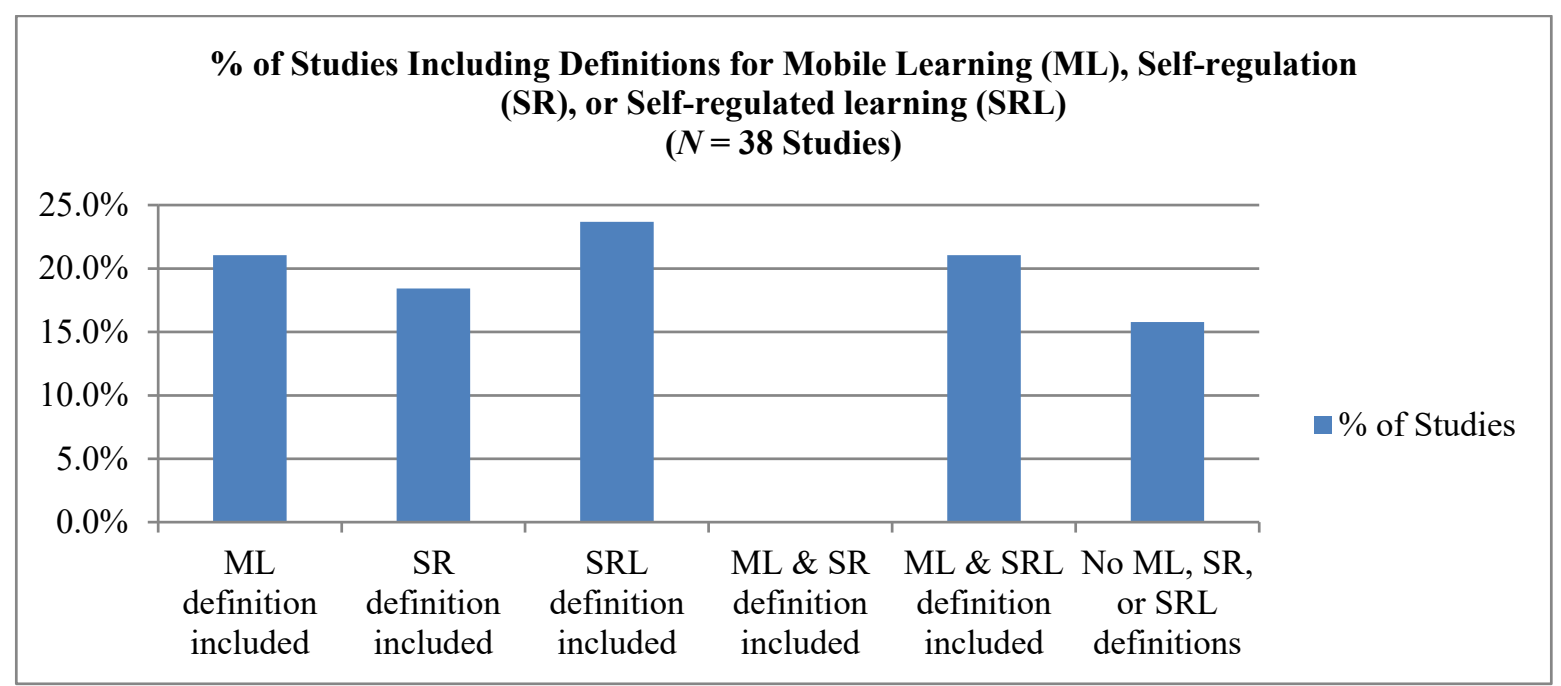

Figure 8. Studies that included definitions for mobile learning, self-regulation, or self-regulated learning $(N=$ 38)

\section{Self-regulated learning definitions}

Thirty $(78.9 \%)$ studies included definitions for the terms, self-regulation, and self-regulated learning, yielding a total of 85 coded units (one unit $=$ one sentence). Six provided author definitions. A further 66 external sources were cited in the rest of the studies that defined SRL: $33(50 \%)$ of these were cited only once. Fifteen $(25 \%)$ of the remaining external citations came from various works by Zimmerman $(1990,1998,2000)$ and Zimmerman and Schunk (2001), and 12 by Pintrich $(1999,2000)$ and Pintrich and De Groot (1990). These works defined the term SRL.

A distillation of Zimmerman's definitions provided in the studies presents SRL as active, self-directed processes in which beliefs, thoughts, and feelings are transformed into academic tasks with the support of intrinsic motivation and metacognitive abilities. Aggregated results pointed to Pintrich's definition of SRL as an active, constructive, and persistent metacognitive process initiated by goal planning, which moves on to monitoring and controlling self-motivation, cognition, and behaviour, before attaining contextual understanding and goal achievement. A synthesis of Zimmerman's and Pintrich's themes yields a definition for SRL that theoretically aligns with a self-directed/self-determined learning paradigm, cognitivist and constructivist notions, and activity theory. Therefore, a composite of their definitions presents SRL as active, self-directed processes involving: goal-planning; monitoring and controlling cognitions, motivations, and behaviours aimed at fulfilling goals; and achievement of goals. The concept of SRL is expanded upon in the discussion of the SRL models used in the reviewed studies.

\section{Mobile learning definitions}

Seventeen external sources were cited in the $16(41.2 \%)$ studies that provided definitions for the term, mobile learning. Works by Sharples and colleagues (e.g., Sharples et al., 2005, 2007) were cited in four (25\%) studies; no other sources were cited in more than one study. Four $(25 \%)$ studies offered their own definitions without reference to external sources.

A total of 55 coded units (one unit $=$ one sentence) were identified in the definitions for m-learning. Five thematic areas were identified among these units. The most prevalent theme was pedagogy, which was 
mentioned in 17 (31\%) units. Most common sub-themes included learner-determined paradigm, activity theory, learner-centric approach, and integrated curriculum. The second theme concerned the learning context/environment (representing 15 units; 27\%). Most frequently mentioned sub-themes were: mobile spaces and settings; multiple contexts; and the affordance of right time, right place. Thirteen (24\%) units highlighted the role that mobile devices played in m-learning. Only one focused primarily upon the mobility of the devices. Seven (13\%) considered learner characteristics, such as learner mobility, motivation, and self-regulation of learning. In their work, Sha, Looi, Chen, and Zhang (2012) advocated for greater recognition of learner characteristics in any learner-centred m-learning curriculum. Perhaps one step towards achieving this goal would be for authors to include this theme in their definitions of m-learning. It is also worth noting that while Sharples, Sanchez, Milrad, and Vavoula (2006) observed that the trend was to focus upon the mobility of the learner rather than on the devices when discussing m-learning, learner mobility was only mentioned in nine (24\%) studies offering definitions for m-learning. The final thematic area, found in three $(5 \%)$ units, was activities. Sub-themes included the value of m-learning for acquiring knowledge, information, or course content. A synthesis of these findings characterises m-learning as an active process employing mobile technologies that enable learners to access, create, curate, and share knowledge and information within and across learner-determined spaces, places, and time frames.

\section{Question 5. Models and variable measurement instruments}

\section{Models}

Fifteen of the 38 studies (39.5\%) reported applying a specific validated model. The three most frequently cited models focused on SRL. In order from most to least common, these models are the cyclical phases of SRL, multi-level model, and COPES (conditions, operations, products, evaluations, standards) model.

The majority of the reviewed studies, that is, seven (18.4\%; e.g., Chien, 2016), referred to three successive versions of the cyclical phases of SRL model by Zimmerman and colleagues (Zimmerman, 2000; Zimmerman \& Campillo, 2003; Zimmerman \& Moylan, 2009). At the individual level, the model detailed "the interrelation of metacognitive and motivational processes" (Panadero, 2017, p. 422) and "how metacognitive and motivational processes and beliefs interact during successive feedback cycles" (Panadero \& Alonso-Tapia, 2014; p. 458). Based upon social cognitive theory, the model consisted of three phases (forethought, performance, and SR), with particular emphasis on how motivation affected SR (Panadero \& Alonso-Tapia, 2014). Although sub-phases were included in Zimmerman's original work (2000), they were not embedded in the graphic representation of SR until Zimmerman and Campillo's (2003) work. Minor tweaks, as well as new metacognitive and volitional strategies in the performance phase, were added to the model by Zimmerman and Moylan in 2009.

Four studies (10.5\%) (Appendix A) included the multi-level model (Zimmerman, 2000), which represents four stages wherein learners acquire self-regulatory competency. These stages comprise observation, emulation, self-control, and SR levels (Panadero, 2017). The model also "identifies four features of regulation: source of regulation, source of motivation, task conditions, and performance indices" (Zimmerman, 2013, p. 140). It explores the social aspects of the regulation of learning and the importance of social levels in developing SR. Zimmerman (2013) theorised "that there [are] four levels in a social cognitive path to self-regulation with the first two levels being social and the last two being self in focus" (p. 140).

Finally, four other articles reporting on three different studies (10.5\%; e.g., Looi \& Wong, 2014) adopted the Winne's or Winne and Hadwin's (1998) models. Winne's (2001) COPES model evolved from Winne and Hadwin's (1998) model and was influenced by Winne's (2001) information processing theory. The acronym, COPES, is derived from the model: (1) conditions includes available resources and constraints associated with a task or environment; (2) operations involves the learner's cognitive processes, tactics, and strategies, which Winne (2001) refers to as SMART: searching, monitoring, assembling, rehearsing, and translating; (3) products consist of the new knowledge created by operations; (4) evaluations includes self-, peer-, and/or teacher feedback, and (5) standards; criteria that products are monitored by (Winne \& Hadwin, 1998). The model expresses SR as agency, suggesting that learning is an iterative, complex process "powered by SRL across four linked phases" (Panadero, 2017, p. 422). These phases include task definition, goal setting and planning, 
studying tactics (enacting), and making adaptations to metacognition. A self-regulated learner is characterised as being highly active cognitively and meta-cognitively (Winne, 2011). As these models are not specific to the m-learning context, Sha and colleagues (2012), and subsequently, Looi and Wong (2014) proposed an analytic SRL model of m-learning to explore the relationship between m-learning and SRL. This conceptual framework considered the notion of agency to be central to the model. SR as agency referred to "the learner characteristics that function as internal driving forces initiating and sustaining a self-regulated m-learning process" (Looi \& Wong, 2014, p. 77). Accordingly, m-learning processes were considered as manifestation of SRL during which self-regulating learners actively applied their agency to control their own behaviour and cognition (Looi \& Wong, 2014; Sha, Looi, Chen, Seow, \& Wong, 2012; Sha, Looi, Chen, \& Zheng, 2012). The authors observed that m-learning environments, due to the ubiquity, flexibility, and portability of mobile technologies, were particularly conducive to learners exercising their agency and using mobile devices as cognitive and metacognitive tools.

From the remaining 23 articles, 3 (7.9\%) did not refer to any models at all and the other 20 (52.6\%) adapted and combined a variety of other existing models (excluding those mentioned above) for the specific contexts of their studies. No other model was offered to examine the SRL/m-learning relationship.

Variable measurement instruments

Eighteen studies (47.4\%) used one instrument, 17 (44.7\%) used two, 1 study (2.6\%) used three, and 2 studies (5.3\%) used four instruments (Table 2). The most popular questionnaires were the Motivated Strategies for Learning Questionnaire (MSLQ) (Pintrich \& De Groot, 1990; Pintrich, Smith, Garcia, \& McKeachie, 1993) and the Online Self-regulated Learning Questionnaire (OSLQ) (Barnard, Lan, To, Paton, \& Lai, 2009). MSQL was applied in 9 studies, although it was modified in some instances. Three studies used OSLQ (an adaptation of the MSQL for online and blended learning contexts). Other questionnaires were used in single studies, for instance, Emotion Regulation Questionnaire (ERQ) (Elhai et al., 2018) and Metacognitive Awareness Inventory (MAI) (Lee, 2013). When using their own questionnaires, 13 studies included items concerning SR(L), and 14 measured other aspects of learning or m-learning behaviours. Additional data came from learning analytics, focus groups, interviews, videos, observations, achievement assessments, and self-reports.

Table 2

Variable measurement instruments used in studies

Instruments used \# of studies

Existing questionnaires - SRL items:

- Motivated strategies for learning questionnaire (MSLQ) (Pintrich et al., 1990, 1993) 9

- Online self-regulated learning questionnaire (OSLQ) (Barnard et al., 2009) 3

- $\quad$ Learning self-regulation questionnaire (SRQ-L) (Williams \& Deci, 1996) 1

- Self-regulation scale (Schwarzer, Diehl, \& Schmitz, 1999) 1

- Emotion regulation questionnaire (ERQ) (Gross \& John, 2003) 1

- Metacognitive awareness inventory (MAI) (Schraw \& Dennison, 1994) 1

Existing questionnaires - other items 4

Original author-created questionnaires - SRL Items 13

Original author-created questionnaires - other items 14

$\begin{array}{ll}\text { Learner analytics } & 4\end{array}$

Focus groups, interviews, video, observations, achievement assessments, self-reports $\quad 12$

\section{Conclusion}

This systematic review provided a synthesis of key findings on 12 research elements from 38 primary research studies, published over 12 years, ending in January, 2019. The goal was to inform social science professionals about the most prevalent research aims, methodologies, definitions, models, and outcomes on the relationship between m-learning and SRL over these years. 
Research aims focused upon m-learning and SRL strategies, impacts, and relationships. While older studies dwelt upon the use of mobile devices and the influence of m-learning on SRL, most current studies explored the interrelationships between m-learning, SRL, and other factors that impacted learning. Three quarters of the studies reported positive results, with most indicating that either m-learning and SRL enhanced other learning factors, or that m-learning improved SRL - not m-learning understood as using mobile devices for learning, but rather by its affordances, such as flexibility and personalisation. Studies examining the effect of mobile device use on SRL produced neutral results or indicated that mobile devices inhibited SRL. While most study aims and outcomes were correlated, five studies (13.2\%) that sought to determine the effects of m-learning on SRL concluded that it was the interrelationship between m-learning and SRL that impacted other learning factors. Analysis of study aims and outcomes suggested increasing recognition that the relationship between m-learning and SRL reflects the dynamic, individualistic, and messy nature of learning (Wark, 2018).

Other prevalent results indicate that most studies:

- were cross-sectional and longitudinal, and used either quantitative or mixed methods,

- focused upon language acquisition, multiple disciplines, or science; involved undergraduate or elementary school children; and were undertaken in blended learning contexts,

- were conducted across the northern hemisphere; data was typically gathered over one 13-week semester; and the number of published studies increased in recent years, perhaps due to the growing ubiquity of mobile devices, and

- involved the use of smartphones, although more recent studies included a combination of smartphones, tablets, and/or other types of devices, possibly reflecting the rapid spread of emergent technologies and increase in learner mobility.

Based upon the synthesis of definitions offered in the reviewed studies, m-learning is defined as an active process employing mobile technologies that enable learners to access, create, curate, and share knowledge and information within and across learner-determined spaces, places, and time frames. Distillation of study definitions for the term, SRL, presents SRL as active, self-directed processes involving: goal-planning; monitoring and controlling cognitions, motivations, and behaviours aimed at fulfilling goals; and achieving goals.

The three SRL models most frequently cited in the reviewed studies were cyclical phases of SRL (Zimmerman, 2000; Zimmerman \& Campillo, 2003; Zimmerman \& Moylan, 2009), multi-level model (Zimmerman, 2000; 2013), and COPES (Winne, 2001), all referring to the various processes and other enablers involved in SRL. The only model specifically addressing the relationship between SRL and m-learning was the analytic SRL model of m-learning put forth by Sha et al. (2012), and revisited by Looi and Wong (2014).

\section{Review limitations}

This review was mainly limited by: the authors' reliance upon English language, peer-reviewed primary research journal articles found in six databases; the decision to begin the search in 2007, when the first mlearning field study was published (Parsons, 2014); the inclusion of m-learning and SRL in the selected studies; and choosing only studies conducted in formal education settings. No studies were conducted in postgraduate settings and only a few disciplines were represented: 27 (71\%) studies came from languages, multi-disciplines, and science.

The review was also hampered by missing data and inadequate research rigour in some of the reviewed studies (which were, nevertheless, included in the review to provide a complete picture of the peer-reviewed literature published on the topic). The fact that some of these studies were completed in one day and only three (8\%) of the articles clearly specified the length of the study period highlights a need for more rigorous research methodology and reporting. This also raises questions about the findings disseminated in some publications. Five articles (13\%) did not mention where their research was conducted, hence the review authors had to guess 
the location and time frame of these studies using the publication date and other available information. Similarly, the types of mobile devices or technologies used were not specified in eight (21\%) studies, which raises questions about the m-learning aspect of the research context. Additional concerns about the theoretical grounding of some of the reported research come from the lack of clear conceptual frameworks and definitions: only $16(42 \%)$ articles defined m-learning; 30 (79\%) provided definitions of SRL; none of the studies offered definitions for both m-learning and SRL; and $6(16 \%)$ shared no definitions for any of these concepts. This emphasises the importance for researchers "to be more explicit about the theories that underpin their studies" (Hew, Lan, Tang, Jia, \& Lo, 2019, p. 13) and to ensure that their studies are not undertheorised, as claimed by critics of educational technology research (Hew et al., 2019).

\section{Key implications for educational stakeholders}

The authors identified a number of further implications for educational stakeholders. First, m-learning designers and practitioners should ensure that mobile technologies are used intentionally and selectively, with clearly defined learning objectives in mind. In fact, numerous studies advised that m-learning and SRL most effectively enhanced learning when they were intentionally integrated into the curriculum and guided by informed, technologically-adept educators who provide appropriate, ever-decreasing support and scaffolding as learners become more self-determined (e.g., Kondo et al., 2012). Second, when designing m-learning, educators should consider digital safety and privacy issues. These issues were not addressed sufficiently in the reviewed studies but, in the long run, can significantly limit learners' self-regulation and m-learning experiences. Third, mlearning research and practice should be founded upon relevant theory and validated definitions of m-learning that consider ever-advancing mobile technologies and related pedagogies that include learner-centred participatory activities.

\section{Research recommendations}

In terms of research recommendations, future studies may provide deeper understanding and more comprehensive validation of studies if researchers meticulously detailed methodologies (e.g., research paradigm/theoretical foundation, methodology, methods, participant details and numbers, research contexts, data collection dates and time frames), key term definitions and how they are operationalised, and types of devices used in studies. It is also recommended that more studies be conducted beyond elementary and undergraduate university settings, and that study time frames be extended to better understand how m-learning and SRL impact lifelong, life-wide learning. Only one qualitative study was included in this review, offering significant opportunity for future research that could provide the academic community with crucial insight into the complex relationship between SRL and m-learning. Considering the limited representation of educational disciplines, levels, and contexts in the reported studies, research should be expanded to other disciplinary areas, such as math and education, as well as including high school, technical, business, and post-graduate contexts.

In discovering the significant lack of critical data, such as missing, vague, or author-generated definitions for key terms and theoretical frameworks or models in many of the reviewed studies, this review recognises the profound need for educational research on the relationship between m-learning and SRL to be theoreticallygrounded.

\section{Future research}

The next phase of this study considers an in-depth thematic analysis on the interrelationship between mlearning and SRL, based upon the definitions, models, and findings generated from the reviewed publications and other relevant literature. The authors aim to identify key dimensions and elements of this relationship, and to provide further theoretical and practical guidance to educational stakeholders on how it can be leveraged to enhance learning. 


\section{References}

Alonso-Mencía, M. E., Alario-Hoyos, C., Maldonado-Mahauad, J., Estévez-Ayres, I., Pérez-Sanagustín, M., \& Delgado Kloos, C. (2019). Self-regulated learning in MOOCs: Lessons learned from a literature review. Educational Review, 18(3), 1-27. https://doi.org/10.1080/00131911.2019.1566208

Barnard, L., Lan, W. Y., To, Y. M., Paton, V. O., \& Lai, S. L. (2009). Measuring self-regulation in online and blended learning environments. The Internet and Higher Education, 12(1), 1-6. https://doi.org/10.1016/j.iheduc.2008.10.005

Berge, Z. L., \& Muilenburg, L. (Eds.). (2013). Handbook of mobile learning. New York, NY: Routledge. https://doi.org/10.4324/9780203118764

Britten, N., Campbell, R., Pope, C., Donovan, J., Morgan, M., \& Pill, R. (2002). Using meta-ethnography to synthesize qualitative research: A worked example. Journal of Health Services Research and Policy, 7(4), 209-215. https://doi.org/10.1258/135581902320432732

Broadbent, J., \& Poon, W. L. (2015). Self-regulated learning strategies \& academic achievement in online higher education learning environments: A systematic review. The Internet and Higher Education, 27, 13. https://doi.org/10.1016/j.iheduc.2015.04.007

Brynjolfsson, B., \& McAfee, A. (2014). The second machine age: Work, progress, and prosperity in a time of brilliant technologies. W. W. Norton \& Company. https://doi.org/10.1080/14697688.2014.946440

Chien, C. W. (2016). Taiwanese EFL undergraduates' self-regulated learning with and without technology. Innovation in Language Learning and Teaching, 13(1), 1-16. https://doi.org/10.1080/17501229.2016.1264076

Cohen, L., Manion, L., \& Morrison, K. (2011). Research methods in education (7th ed.). London: Routledge.

Crompton, H. (2014). A diachronic overview of technology contributing to mobile learning: A shift towards student-centred pedagogies. In M. Ally, \& A. Tsinakos (Eds.), Perspectives on open and distance learning: Increasing access through mobile learning (pp. 7-16). Vancouver: OAsis. http://oasis.col.org/handle/11599/558

Crompton, H., \& Burke, D. (2018). The use of mobile learning in higher education: A systematic review. Computers \& Education, 123, 53-64. https://doi.org/10.1016/j.compedu.2018.04.007

DiFilippo, K. N., Huang, W. H., Andrade, J. E., \& Chapman-Novakofski, K. M. (2015). The use of mobile apps to improve nutrition outcomes: A systematic literature review. Journal of Telemedicine and Telecare, 21(5), 243-253. https://doi.org/10.1177/1357633X15572203

Dunleavy, G., Nikolaou, C. K., Nifakos, S., Atun, R., Law, G. C. Y., \& Car, L. T. (2019). Mobile digital education for health professions: Systematic review and meta-analysis by the digital health education collaboration. Journal of Medical Internet Research, 21(2), e12937. https://doi.org/10.2196/12937

Elhai, J. D., Tiamiyu, M. F., Weeks, J. W., Levine, J.C., Picard, K. J., \& Hall, B. J. (2018). Depression and emotion regulation predict objective smartphone use measured over one week. Personality and Individual Differences, 133(15), 21-28. https://doi.org/10.1016/j.paid.2017.04.051

Gough, D., Oliver, S., \& Thomas, J. (2012). Introducing systematic reviews. In D. Gough, S. Oliver, \& J. Thomas (Eds.), An introduction to systematic reviews (pp. 1-16). London, UK: SAGE Publications. https://uk.sagepub.com/en-gb/eur/an-introduction-to-systematic-reviews/book245742

Hemingway, P., \& Brereton, N. (2009). What is a systematic review? In Hayward Medical Group (Ed.), Evidence-based medicine (2nd ed.), (pp. 1-8). Sheffield, UK: Hayward Medical Communications. https://familymedicine.med.wayne.edu/mph/project/what is_a systematic_review.pdf

Hew, K. F., Lan, M., Tang, Y., Jia, C., \& Lo, C. K. (2019). Where is the "theory" within the field of educational technology research? British Journal of Educational Technology, 50(3), 956-971. https://doi.org/10.1111/bjet.12770

International Telecommunication Union (2018). Measuring the Information society report, 2018. ITU: Committed to connecting the world. https://www.itu.int/en/ITUD/Statistics/Pages/publications/misr2018.aspx

Kondo, M., Ishikawa, Y., Smith, C., Sakamoto, K., Shimomura, H., \& Wada, N. (2012). Mobile assisted language learning in university EFL courses in Japan: Developing attitudes and skills for self-regulated learning. ReCALL, 24(2), 169-187. https://doi.org/10.1017/S0958344012000055 
Krull, G., \& Duart, J. M. (2017). Research trends in mobile learning in higher education: A systematic review of articles (2011-2015). International Review of Research in Open and Distributed Learning, 18(7). https://doi.org/10.3991/ijim.v8i4.3991

Kumar, B. A., \& Mohite, P. (2018). Usability of mobile learning applications: A systematic literature review. Journal of Computers in Education, 5(1), 1-17. https://doi.org/10.1007/s40692-017-0093-6

Lee, C. B. (2013). Exploring the relationship between intention to use mobile phone as a visualization tool and regulation of cognition. Computers \& Education, 60(1), 138-147. https://doi.org/10.1016/j.compedu.2012.08.003

Looi, C. K., \& Wong, L. H. (2014). Implementing mobile learning curricula in schools: A programme of research from innovation to scaling. Journal of Educational Technology \& Society, 17(2). https://doi.org/10.1080/10494820.2012.745424

Moher, D., Liberati, A., Tetzlaff, J., Altman, D. G., \& The PRISMA Group. (2009). Preferred reporting items for systematic reviews and meta-analyses: The PRISMA statement. PLoS Med 6(7). https://doi.org/10.1371/journal.pmed1000097

Moher, D., Shamseer, L., Clarke, M., Ghersi, D., Liberati, M. Shekelle, P., Stewart, L. A., \& PRISMA-P Group. (2015). Preferred reporting items for systematic review and meta-analysis protocols (PRISMA-P) 2015 statement. Systematic Reviews, 4(1), https://doi.org/10.1186/2046-4053-4-1

Mosa, A. S. M., Yoo, I., \& Sheets, L. (2012). A systematic review of healthcare applications for smartphones. BMC Medical Informatics and Decision Making, 12(1), 67. https://doi.org/10.1186/1472-6947-12-67

Oakley, A. (2012). Foreword. In D. Gough, S. Oliver, \& J. Thomas (Eds.), An introduction to systematic reviews (pp. vii-x). London: SAGE Publications. https://uk.sagepub.com/en-gb/eur/an-introduction-tosystematic-reviews/book 245742

O’Malley, C., Vavoula, G., Glew, J. P., Taylor, J., Sharples, M., \& Lefrere, P. (2003). Guidelines for learning/teaching/tutoring in a mobile environment (MOBIlearn Project Report D4.1). https://hal.archives-ouvertes.fr/hal-00696244/document

Onwuegbuzie, A. J., \& Leech, N. L. (2005). On becoming a pragmatic researcher: The importance of combining qualitative and quantitative research methodologies. Journal of Social Research Methodology, 8(5), 375-387. https://doi.org/10.1080/13645570500402447

Palalas, A., \& Wark, N. (2017). Design principles for an adult literacy mobile learning solution. In F. Loizides \& G. Papadopoulos (Eds.), mLearn 2017: Proceedings of the 16th World Conference on Mobile and Contextual Learning (pp. 27-35). New York, NY: ACM. https://doi.org/10.1145/3136907.3136934

Panadero, E. (2017). A review of self-regulated learning: Six models and four directions for research. Frontiers in Psychology, 28(8), 422. https://doi.org/10.3389/fpsyg.2017.00422

Panadero, E., \& Alonso-Tapia, J. (2014). How do students self-regulate? Review of Zimmerman's cyclical model of self-regulated learning. Anales de Psicologia/Annals of Psychology, 30(2), 450-462. https://doi.org/10.6018/analesps.30.2.167221

Parsons, D. (2014). A mobile learning overview by timeline and mind map. International Journal of Mobile and Blended Learning, 6(4), 1-21. https://www.igi-global.com/gateway/article/163897

Pegrum, M. (2014). Mobile learning: Languages, literacies and cultures. London: Palgrave Macmillan. https://doi.org/10.1057/9781137309815

Pimmer, C., Mateescu, M., \& Grohbiel, U. (2016). Mobile and ubiquitous learning in higher education settings: A systematic review of empirical studies. Computers in Human Behavior, 63, 490-501. https://doi.org/10.1016/j.chb.2016.05.057

Pintrich, P. R. (1999). The role of motivation in promoting and sustaining self-regulated learning. International Journal of Educational Research, 31(6), 459-470. https://doi.org/10.1016/S08830355(99)00015-4

Pintrich, P. R. (2000). The role of goal orientation in self-regulated learning. In M, Boekaerts, P. R. Pintrich, \& M. Zeidner (Eds.), Handbook of self-regulation (pp. 451-502). Elsevier. https://doi.org/10.1016/B978012109890-2/50043-3

Pintrich, P. R., \& De Groot, E. V. (1990). Motivational and self-regulated learning components of classroom academic performance. Journal of Educational Psychology, 82(1), 33-40. https://doi.org/10.1037/0022$\underline{0663.82 .1 .33}$ 
Pintrich, P. R., Smith, D. A., Garcia, T., \& McKeachie, W. J. (1993). Reliability and predictive validity of the Motivated Strategies for Learning Questionnaire (MSLQ). Educational and Psychological Measurement, 53(3), 801-813. https://doi.org/10.1177/0013164493053003024

Quinn, C. (2012). The mobile academy: mLearning for higher education. San Francisco, CA: Jossey-Bass.

Rodger, H., \& Glover, I. (2018). The death of 'mobile learning.' In H. Crompton, \& J. Traxler (Eds.), Mobile learning and higher education (pp. 94-103). New York, NY: Routledge. https://doi.org/10.4324/9781315296739

Sandelowski, M., Voils, C. J., Leeman, J., \& Crandlee, J. L. (2011). Mapping the mixed methods: Mixed research synthesis terrain. Journal of Mixed Methods Research, 6(4), 317-331. https://doi.org/10.1177/1558689811427913

Sharples, M. (2000). The design of personal mobile technologies for lifelong learning. Computers \& Education, 34(3-4), 177-193. https://doi.org/10.1016/S0360-1315(99)00044-5

Sharples, M., Sanchez, I. A., Milrad, M., \& Vavoula, G. (2006). Mobile learning: Small devices, big issues. In N. Balacheff, S. Ludvigsen, T. de Jong, A. Lazonder, \& S. Barnes (Eds,), Technology-enhanced learning (pp. 233-249). Cham: Springer. https://link.springer.com/book/10.1007/978-3-319-02600-8

Sharples, M., Taylor, J., \& Vavoula, G. (2005). Towards a theory of mobile learning. Paper presented at the mLearn 2005 Conference, Cape Town.

Sharples, M., Taylor, J., \& Vavoula, G. (2007). A theory of learning for the mobile age. In R. Andrews, \& C. Haythornthwaite (Eds.), The SAGE handbook of elearning research (pp. 221-247). London: Sage Publications. https://doi.org/10.1007/978-3-531-92133-4_6

Schraw, G., \& Dennison, R. S. (1994). Assessing metacognitive awareness. Contemporary Educational Psychology, 19(4), 460-475. https://doi.org/10.1006/ceps.1994.1033

Schwarzer, R., Diehl, M. \& Schmitz, G.S. (1999). The self-regulation scale. Berlin: Freie Universitat. http://userpage.fu-berlin.de/ health/selfreg_g.htm

Sha, L., Looi, C. K., Chen, W., Seow, P., \& Wong, L. H. (2012). Recognizing and measuring self-regulated learning in a mobile learning environment. Computers in Human Behavior, 28(2), 718-728. https://doi.org/10.1016/j.chb.2011.11.019

Sha, L., Looi, C. K., Chen, W., \& Zhang, B. H. (2012). Understanding mobile learning from the perspective of self-regulated learning. Journal of Computer Assisted Learning, 28(4), 366-378. https://doi.org/10.1111/j.1365-2729.2011.00461.x

Traxler, J. (2007). Defining, discussing and evaluating mobile learning: The moving finger writes and having writ..., International Review of Research in Open and Distributed Learning, 8(2). https://doi.org/10.19173/irrodl.v8i2.346

Wark, N. (2018). Shifting paradigms: A critical pragmatic evaluation of key factors affecting learnerempowered emergent technology integration (Doctoral dissertation). Athabasca University, Canada. http://hdl.handle.net/10791/274

Winne, P. H. (2001). Self-regulated learning viewed from models of information processing. In B. J. Zimmerman, \& D. H. Schunk (Eds.), Self-regulated learning and academic achievement: Theoretical perspectives (pp. 153-189). Mahwah, NJ: Erlbaum.

Winne, P. H. (2011). A cognitive and metacognitive analysis of self-regulated learning. In B. J. Zimmerman, \& D. H. Schunk (Eds.), Handbook of self-regulation of learning and performance (pp. 15-32). New York, NY: Routledge. https://doi.org/10.4324/9781315697048

Winne, P. H., \& Hadwin, A. F. (1998). Studying as self-regulated engagement in learning. In D. J. Hacker, J. Dunlosky, \& A. Graesser (Eds.), Metacognition in educational theory and practice (pp. 277-304). Hillsdale, NJ: Erlbaum.

Wong, J., Baars, M., Davis, D., van der Zee, T., Houben, G.-J., \& Paas, F. (2019). Supporting self-regulated learning in online learning environments and MOOCs: A systematic review. International Journal of Human-Computer Interaction, 35(4-5), 356-373. https://doi.org/10.1080/10447318.2018.1543084

Zimmerman, B. J. (1990). Self-regulated learning and academic achievement: An overview. Educational Psychologist, 25(1), 3-17. https://doi.org/10.1207/s15326985ep2501_2

Zimmerman, B. J. (1998). Developing self-fulfilling cycles of academic regulation: An analysis of exemplary instructional models. In D. H. Schunk, \& B. J. Zimmerman (Eds.), Developing self-regulated learners: From teaching to self-reflective practice (pp. 13-39). New York, NY: Guilford Press. 
Zimmerman, B. J. (2000). Self-efficacy: An essential motive to learn. Contemporary Educational Psychology, 25(1), 82-91. https://doi.org/10.1006/ceps.1999.1016

Zimmerman, B. J. (2008). Investigating self-regulation and motivation: Historical background, methodological developments, and future prospects. American Educational Research Journal, 45(1), 166183. https://doi.org/10.3102/0002831207312909

Zimmerman, B. J. (2013). From cognitive modeling to self-regulation: A social cognitive career path. Educational Psychologist, 48(3), 135-147. https://doi.org/10.1080/00461520.2013.794676

Zimmerman B. J., \& Campillo M. (2003). Motivating self-regulated problem solvers. In J. E. Davidson, \& R. J. Sternberg (Eds.), The psychology of problem solving (pp. 233-262). Cambridge: Cambridge University Press.

Zimmerman, B. J., \& Moylan, A. R. (2009). Self-regulation: Where metacognition and motivation intersect. In D. J. Hacker, J. Dunlosky, \& A. C. Graesser (Eds.), The educational psychology series. Handbook of metacognition in education (p. 299-315). New York, NY: Routledge.

Zimmerman, B. J., \& Schunk, D. H. (2001). Reflections on theories, identities, and actions of self-regulated learners. In B. J. Zimmerman, \& D. H. Schunk (Eds.), Self-regulated learning and academic achievement: Theoretical perspectives (pp. 289-307). Mahwah, NJ: Erlbaum.

Corresponding author: Agnieszka Palalas, agapalalas@athabascau.ca

Copyright: Articles published in the Australasian Journal of Educational Technology (AJET) are available under Creative Commons Attribution Non-Commercial No Derivatives Licence (CC BY-NC-ND 4.0). Authors retain copyright in their work and grant AJET right of first publication under CC BY-NC-ND 4.0.

Please cite as: Palalas, A., \& Wark, N. (2020). The relationship between mobile learning and learner selfregulation: A systematic review. Australasian Journal of Educational Technology, 36(4), 151-172. https://doi.org/10.14742/ajet.5650 


\section{Appendix A Complete list of reviewed studies}

Reviewed Study $(N=38)$ arranged by number of citations

\# of

citations

189

Sha, L., Looi, C. K., Chen, W., \& Zhang, B. H. (2012). Understanding mobile learning from the perspective of self-regulated learning. Journal of Computer Assisted Learning, 28(4), 366-378.

Wei, F. Y. F., Wang, Y. K., \& Klausner, M. (2012). Rethinking college students' selfregulation and sustained attention: Does text messaging during class influence cognitive learning? Communication Education, 61(3), 185-204.

Järvelä, S., Näykki, P., Laru, J., \& Luokkanen, T. (2007). Structuring and regulating collaborative learning in higher education with wireless networks and mobile tools. Educational Technology \& Society, 10(4), 71-79.

Gökçearslan, S., Mumcu, F. K., Haşlaman, T., \& Çevik, Y. D. (2016). Modelling smartphone addiction: The role of smartphone usage, self-regulation, general selfefficacy and cyberloafing in university students. Computers in Human Behavior, 63, 639-649.

Tabuenca, B., Kalz, M., Drachsler, H., \& Specht, M. (2015). Time will tell: The role of mobile learning analytics in self-regulated learning. Computers \& Education, 89, 53-74.

David, P., Kim, J., Brickman, J. S., Ran, W., \& Curtis, C. M. (2015). Mobile phone distraction while studying. New Media \& Society, 17(10), 1661-1679.

Sha, L., Looi, C. K., Chen, W., Seow, P., \& Wong, L. H. (2012). Recognizing and measuring self-regulated learning in a mobile learning environment. Computers in Human Behavior, 28(2), 718-728.

Kondo, M., Ishikawa, Y., Smith, C., Sakamoto, K., Shimomura, H., \& Wada, N. (2012). Mobile assisted language learning in university EFL courses in Japan: Developing attitudes and skills for self-regulated learning. ReCALL, 24(2), 169-187.

Shih, K. P., Chen, H. C., Chang, C. Y., \& Kao, T. C. (2010). The development and implementation of scaffolding-based self-regulated learning system for e/m-learning. Educational Technology \& Society, 13(1), 80-93.

Elhai, J. D., Tiamiyu, M. F., Weeks, J. W., Levine, J.C., Picard, K. J., \& Hall, B. J. (2018). Depression and emotion regulation predict objective smartphone use measured over one week. Personality and Individual Differences, 133(15), 21-28.

Jeno, L. M., Grytnes, J. A., \& Vandvik, V. (2017). The effect of a mobile-application tool on biology students' motivation and achievement in species identification: A selfdetermination theory perspective. Computers \& Education, 107, 1-12.

Goh, T. T., Seet, B. C., \& Chen, N. S. (2012). The impact of persuasive SMS on students' self-regulated learning. British Journal of Educational Technology, 43(4), 624-640.

Felisoni, D. D., \& Strommer Godoi, A. (2018). Cell phone usage and academic performance: An experiment. Computers \& Education, 117, 175-187.

Perry, D. R., \& Steck, A. K. (2015). Increasing student engagement, self-efficacy, and meta-cognitive self-regulation in the high school geometry classroom: Do iPads help? Computers in the Schools, 32(2), 122-143.

Wang, Y. H. (2016). Could a mobile-assisted learning system support flipped classrooms for classical Chinese learning? Journal of Computer Assisted Learning, 32(5), 391-415.

Alegría, D. A. H., Boscardin, C., Poncelet, A., Mayfield, C., \& Wamsley, M. (2014). Using tablets to support self-regulated learning in a longitudinal integrated clerkship. Medical Education Online, 19(1). 
Pourrazavi, S., Allahverdipour, H., Jafarabadi, M. A., \& Matlabi, H. (2014). A sociocognitive inquiry of excessive mobile phone use. Asian Journal of Psychiatry, 10, 8489.

Looi, C. K., \& Wong, L. H. (2014). Implementing mobile learning curricula in schools: A programme of research from innovation to scaling. Journal of Educational Technology \& Society, 17(2).

El-Bishouty, M. M., Ogata, H., Ayala, G., \& Yano, Y. (2010). Context-aware support for self-directed ubiquitous-learning. International Journal of Mobile Learning and Organisation, 4(3), 317-331.

Falloon, G. (2017). Mobile devices and apps as scaffolds to science learning in the primary classroom. Journal of Science Education and Technology, 26(6), 613-628.

Zare Bidaki, M., Naderi, F., \& Ayati, M. (2013). Effects of mobile learning on paramedical students' academic achievement and self-regulation. Future of Medical Education Journal, 3(3), 24-28.

Liaw, S. S., \& Huang, H. M. (2015). How factors of personal attitudes and learning environments affect gender difference toward mobile learning acceptance. International Review of Research in Open and Distributed Learning, 16(4).

Foessl, T., Ebner, M., Schoen, S., \& Holzinger, A. (2016). A field study of a video supported seamless-learning-setting with elementary learners. Educational Technology \& Society, 19(1), 321-336.

Read, T., \& Barcena, E. (2016). Metacognition as scaffolding for the development of listening comprehension in a social MALL app. Ried-Revista Iberoamericana De Educacion a Distancia, 19(1), 103-120.

Lai, C. L., Hwang, G. J., \& Tu, Y. H. (2018). The effects of computer-supported selfregulation in science inquiry on learning outcomes, learning processes, and self-efficacy. Educational Technology Research and Development, 66(4), pp. 863-892.

Spook, J. E., Paulussen, T., Paulissen, R., Visschedijk, G., Kok, G., \& van Empelen, P. (2015). Design rationale behind the serious self-regulation game intervention "Balance It": Overweight prevention among secondary vocational education students in the Netherlands. Games for Health Journal, 4(5), 387-400.

Regan, K., Evmenova, A. S., Good, K., Legget, A., Ahn, S. Y., Gafurov, B., \& Mastropieri, M. (2018). Persuasive writing with mobile-based graphic organizers in inclusive classrooms across the curriculum. Journal of Special Education Technology, 33(1), 314.

Lee, C. B. (2013). Exploring the relationship between intention to use mobile phone as a visualization tool and regulation of cognition. Computers \& Education, 60(1), 138-147.

Zheng, L., Li, X., \& Chen, F. (2016). Effects of a mobile self-regulated learning approach on students' learning achievements and self-regulated learning skills. Innovations in Education and Teaching International, 55(6), 616-624.

Hong, J., Hwang, M., Chang, H., Tai, K., Kuo, Y., \& Tsai, Y. (2015). Internet cognitive failure and fatigue relevant to learners' self-regulation and learning progress in English vocabulary with a calibration scheme. Journal of Computer Assisted Learning, 31(5), 450-461.

Bringula, R. P., Alvarez, J. N., Evangelista, M. A., \& So, R. B. (2017). Learner-interface interactions with mobile-assisted learning in mathematics: Effects on and relationship with mathematics performance. International Journal of Mobile and Blended Learning, 9(1), 34-48.

Waluyo, B. (2018). Promoting self-regulated learning with formative assessment and the use of mobile app on vocabulary acquisition in Thailand. Indonesian Journal of English Language Teaching and Applied Linguistics, 3(1), 105-124. 
Lee, H. Y., \& Lee, H. W. (2018). The effects of cross-modality and level of self-regulated learning on knowledge acquisition with smartpads. Educational Technology Research and Development, 66(2), 247-265.

Chu, H. C., Liu, Y. M., \& Kuo, F. R. (2018). A mobile sleep-management learning system for improving students' sleeping habits by integrating a self-regulated learning strategy: Randomized controlled trial. JMIR MHealth and UHealth, 6(10).

Chien, C. W. (2016). Taiwanese EFL undergraduates' self-regulated learning with and without technology. Innovation in Language Learning and Teaching, 13(1), 1-16.

Pellerin, M. (2018). Affordances of new mobile technologies: Promoting learner agency, autonomy, and self-regulated learning. Journal of Interactive Learning Research, 29(3), 343-358.

Chebykin, O. (2016). Psychoemotional dependence on means of mobile communications in students with different demonstrations of emotional maturity. Science and Education, $11,30-34$.

Viberg, O., \& Andersson, A. (2019). The role of self-regulation and structuration in mobile learning. International Journal of Mobile and Blended Learning, 11(4). 